\title{
Effectiveness and safety of tibial nerve stimulation versus anticholinergic drugs for the treatment of overactive bladder syndrome: a meta-analysis
}

\author{
San-Chao Xiong", Liao Peng", Xu Hu, Yan-Xiang Shao, Kan Wu, Xiang Li \\ Department of Urology, Institute of Urology, West China Hospital, Sichuan University, Chengdu, China \\ Contributions: (I) Conception and design: SC Xiong, L Peng; (II) Administrative support: X Li; (III) Provision of study materials or patients: SC \\ Xiong, L Peng; (IV) Collection and assembly of data: YX Shao, L Peng; (V) Data analysis and interpretation: SC Xiong, K Wu; (VI) Manuscript \\ writing: All authors; (VII) Final approval of manuscript: All authors. \\ "These authors contributed equally to this work. \\ Correspondence to: Xiang Li, MD. Professor of Urology, Department of Urology, Institute of Urology, West China Hospital, Sichuan University, 37 \\ Guoxue Lane, Chengdu 610041, China. Email: xiangli87@hotmail.com.
}

\begin{abstract}
Background This meta-analysis aimed to evaluate the efficacy and safety of tibial nerve stimulation (TNS) and anticholinergic drugs (ACDs) for the treatment of overactive bladder syndrome (OAB).

Methods: Qualified studies up to November 3, 2020 were retrieved from PubMed, Embase, the Cochrane Library and Web of Science. Pooled mean differences (MDs) were calculated to evaluate the improvement of micturition frequency per day, nocturia per night, urinary urgency episodes per day, incontinence episodes per day, and voided volume each time. Odd ratios (ORs) were used to assess the discontinuation rate.

Results: A total of 6 RCTs including 291 patients were included. Comparing with those receiving ACDs, patients receiving TNS had a significantly better improvement of urge incontinence episodes (MD =-1.11; 95\% CI: $-1.66,-0.55 ; \mathrm{P}<0.001)$, but had comparable effect on micturition ( $\mathrm{MD}=-0.75 ; 95 \% \mathrm{CI}:-1.78$, $0.28 ; \mathrm{P}=0.16)$, nocturia $(\mathrm{MD}=-1.11 ; 95 \% \mathrm{CI}:-2.93,0.72 ; \mathrm{P}=0.23)$, urgency $(\mathrm{MD}=-0.57 ; 95 \% \mathrm{CI}:-1.93$, $0.79 ; \mathrm{P}=0.41)$ and voided volume $(\mathrm{MD}=11.61 ; 95 \% \mathrm{CI}:-3.95,27.18 ; \mathrm{P}=0.14)$. Moreover, TNS group had a significantly lower discontinuation rate $(\mathrm{OR}=0.13 ; 95 \% \mathrm{CI}: 0.03,0.51 ; \mathrm{P}=0.003)$ during the trials.
\end{abstract}

Discussion: TNS is as effective as ACDs for treating OAB, but with better performance on the decrease of urge incontinence episodes. Besides, TNS appears to be more tolerable than ACDs.

Keywords: Overactive bladder (OAB) syndrome; tibial nerve stimulation (TNS); anticholinergic drugs (ACDs);
meta-analysis

Submitted Feb 05, 2021. Accepted for publication May 07, 2021.

doi: 10.21037/apm-21-339

View this article at: http://dx.doi.org/10.21037/apm-21-339

\section{Introduction}

Overactive bladder $(\mathrm{OAB})$ is a chronic syndrome defined as urinary urgency, frequency and nocturia with or without urge incontinence (1). The prevalence of $\mathrm{OAB}$ is about $16 \%$ in the European and American adult and it increases with age and is approximately $30 \%$ in women over the age of 65 years (2). With such a prevalence, $\mathrm{OAB}$ affects millions of people on their quality of life and medical expenditure $(3,4)$.

Currently, the anticholinergic/muscarinic drugs (ACDs) are the mainstay for the treatment of OAB. Though they have pronounced ability to improve the symptoms of a big amount of patients with $\mathrm{OAB}$, the drug discontinuation is high with a mean rate of $84 \%$ at 12 months, as a result of its systemic anticholinergic side effects, insufficient response and enduring costs $(5,6)$.

Given the limitation mentioned above, there is a growing requirement for other therapy methods that had less side effect, less costs and same therapeutic effect as ACDs. 
Neuromodulation seems to be that very alternative therapy option which is efficient in the treatment of lower urinary tract syndromes with less absolute side effects observed $(7,8)$. Although the specific mechanism of neuromodulation has not been explained clear totally, two potential mechanisms are considered to be possible: activate the afferent fibers and lead to inhibition at a spinal or a supraspinal level; and activate the efferent fibers to the striated urethral sphincter which releases detrusor reflexively (9).

Tibial nerve stimulation (TNS) is one sort of neuromodulation that stimulates the sacral segments of S2/S3 which contains the spinal center of bladder control $(10,11)$. Since firstly introduced in 1999 , TNS has shown significant clinical efficiency of controlling voiding frequency, nocturia, urgency episodes and incontinence episodes and improving quality of life for patients with $\mathrm{OAB}$ (12). Sherif et al. found that both OnabotulinumtoxinA and TNS were effective to refractory idiopathic OAB but TNS had less side effects (13).

Recently, some randomized controlled trails (RCTs) compared the efficiency of TNS and ACDs for the treatment of OAB but their outcomes varied a lot (14-19). Thus, we performed this meta-analysis to compare the efficiency and tolerance between TNS and ACDS for the treatment of $\mathrm{OAB}$. We present the following article in accordance with the PRISMA 2020 reporting checklist (available at http://dx.doi.org/10.21037/apm-21-339).

\section{Methods}

\section{Search strategy}

We performed an extensive search of the database of PubMed, Embase, the Cochrane Library, and Web of Science up to November 3, 2020. Besides, we searched the references of selected articles and reviews to obtain more potentially relevant studies, and we contacted the corresponding author to obtain the unclear and available data at the same time. As the data was extracted from the open-sourced studies rather than proprietary domains, there is no need to obtain an IBR approval in the current work. We formulated the search strategy according to the Participant, Intervention, Comparison, Outcome and Study (PICOS) framework. The search strategies are as following: ((tibial nerve stimulation OR TNS) OR (percutaneous tibial nerve stimulation OR PTNS) OR (transcutaneous tibial nerve stimulation OR TTNS)) AND (Anticholinergic drugs OR antimuscarinic drugs OR (solifenacin OR tolterodine
OR oxybutynin OR imidafenacin OR propiverine OR fesoterodine OR trospium OR darifenacin)) AND (overactive bladder OR overactive urinary bladder OR bladder, overactive OR OAB)

\section{Inclusion and exclusion criteria}

Studies fulfilled the following criteria were involved in our meta-analysis: (I) patients experienced OAB; (II) studies comparing the effects of TNS and ACDs; (III) outcomes reporting evaluation of the indexes including: frequency, urgency, urge incontinence and nocturia before and after treatment; (IV) English literature; (V) RCT.

Repeat publications, sample size $<10$, reviews, superficial abstracts and those without sufficient data to estimate the outcome were excluded.

\section{Selection of studies}

Two authors (SC Xiong and L Peng) respectively screened the title, abstract and results and keywords of each study. Together, we discussed all of included studies to eliminate discrepancies. Then, full texts were screened to further evaluate if the study had met the inclusion criteria and failed to meet the exclusion criteria.

\section{Quality assessment}

The quality levels of the enrolled RCTs were assessed according to the Cochrane Collaboration bias appraisal tool. The methodological quality of each trial was assessed based on the following items: (I) random sequence generation; (II) allocation concealment; (III) blinding of participants and personnel; (IV) blinding of outcome assessment; (V) incomplete outcome data; (VI) selective reporting; (VII) other bias. Each item was assessed with low risk, high risk or unclear.

\section{Data extraction}

Two individual investigators (YX Shao and L Peng) extracted the required data using a standard form. We extracted the following characteristics: name of the first author, publication year, the study design, the dosage and the frequency of treatment patients received, treatment duration, the incidence of side effects, the discontinuation because of an adverse events (AEs), the baseline and outcome micturition per day, urgency episodes, urge 


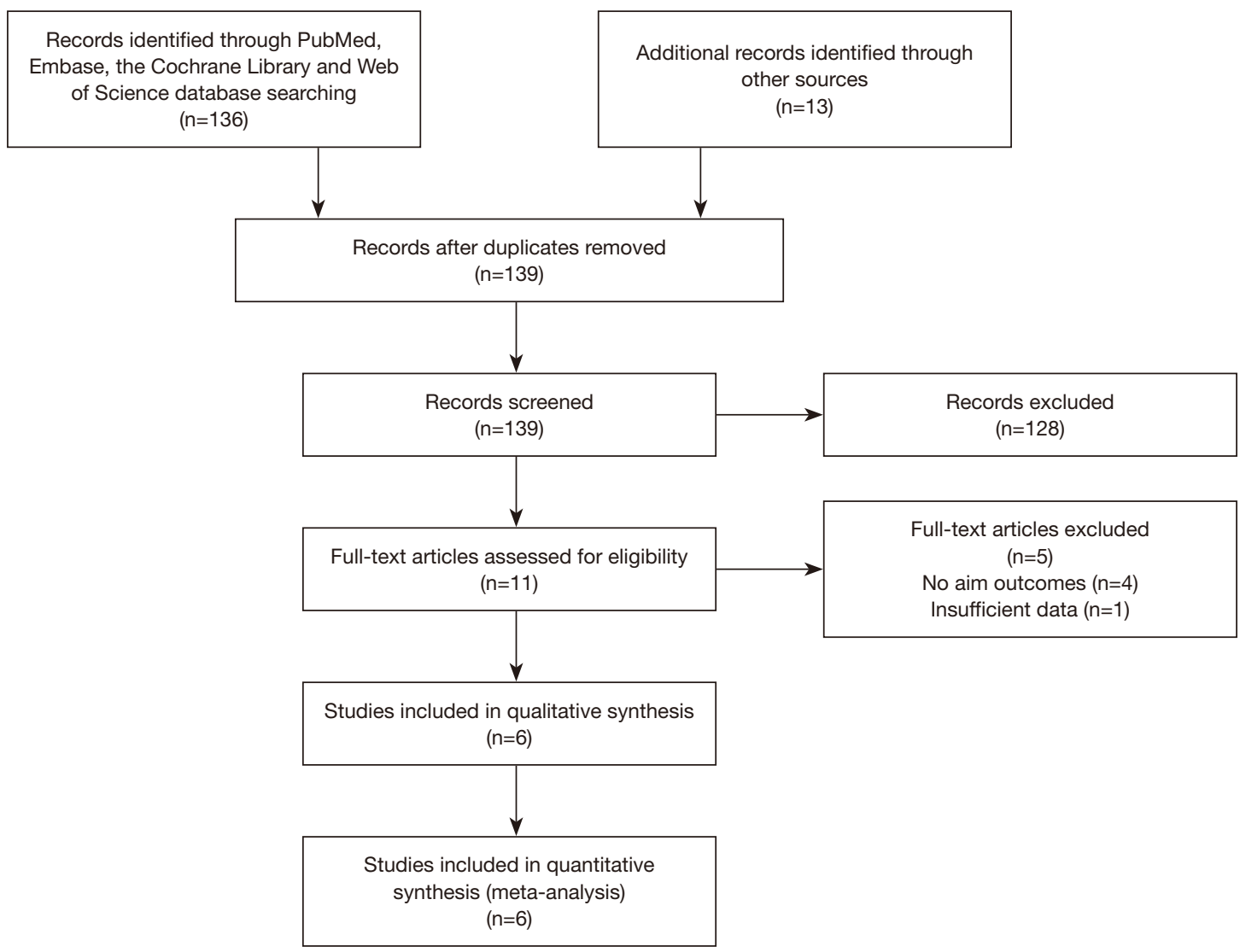

Figure 1 PRISMA flowchart of study selection.

incontinence episodes per day, nocturia per night, Patien Global Impression of Improvement questionnaire (PGI-I), Overactive Bladder questionnaire Short Form 6 items (OAB-q SF 6) and Overactive Bladder questionnaire Short Form 13 items (OAB-q SF 13). At the same time, the authors of original studies were requested for authentic information when we imputed the missing or vague information based on the methods of Cochrane Handbook.

\section{Statistical analysis}

The pooled effects were expressed as the mean differences (MDs) for continuous outcomes and odds ratios (ORs) for dichotomy variable with $95 \%$ CIs. The heterogeneity of the enrolled studies was assessed according to Higgins $\mathrm{I}^{2}$ and the Cochrane's Q-statistic test (20). When there was no conspicuous heterogeneity ( $\mathrm{P}>0.1$ or $\left.\mathrm{I}^{2} \leq 50 \%\right)$, a fixed model (Mantel-Haenszel method) was used; otherwise, a random model (DerSimonian-Laird method) was applied $(21,22)$. A two-sided $\mathrm{P}<0.05$ were considered statistically significant.
By removing each study sequentially, sensitivity analyses were performed to evaluate the stability of the final results. All these are dealt with Review Manager 5.3.

\section{Results}

\section{Characteristics of individual studies}

Figure 1 displayed the study selection process. Based on the inclusion and exclusion criteria, a total of 139 articles were retrieved in initial search, and 6 studies (14-19) including $291 \mathrm{OAB}$ patients were finally enrolled in the current metaanalysis and all the studies included were RCTs. Table 1 list the characteristics of the included studies in the metaanalysis. The treatment duration of 3 studies $(14,15,18)$ was 12 weeks, two $(16,17)$ was 3 months and one (19) was 6 weeks. The therapeutic methods of TNS were once a week for $30 \mathrm{~min}$ in the most of studies (14,16-18) except 2 studies $(15,19)$ in which it was twice a week for $30 \mathrm{~min}$. The choice of ACDs varied: oxybutynin in one study (15), solifenacin 
Table 1 Characteristics of the included studies in meta-analysis

\begin{tabular}{|c|c|c|c|c|c|c|c|c|c|}
\hline Author & Year & Country & Gender & $\begin{array}{l}\text { Intervention/ } \\
\text { comparison }\end{array}$ & No. & $\begin{array}{c}\text { Mean age } \pm \\
\text { SD }\end{array}$ & $\begin{array}{l}\text { Treatment } \\
\text { protocol }\end{array}$ & $\begin{array}{l}\text { Follow- } \\
\text { up }\end{array}$ & Comparable index \\
\hline \multirow[t]{2}{*}{ Vecchioli } & \multirow[t]{2}{*}{2013} & \multirow[t]{2}{*}{ Italy } & \multirow[t]{2}{*}{ Female } & PTNS & 16 & $66.7 \pm 8.8$ & $\begin{array}{l}\text { Twice/week for } \\
30 \mathrm{~min}\end{array}$ & 6 weeks & \multirow{2}{*}{$\begin{array}{c}\text { Micturition, nocturia, } \\
\text { urge incontinence, } \\
\text { voided volume, AEs, } \\
\text { OAB-qSF 6, OAB- } \\
\text { qSF13 and PGI-I }\end{array}$} \\
\hline & & & & $\begin{array}{l}\text { Solifenacin } \\
\text { succinate }\end{array}$ & 14 & $66.3 \pm 9.7$ & $5 \mathrm{mg} /$ day & 40 days & \\
\hline Vecchioli & 2018 & Italy & Female & $\begin{array}{l}\text { Solifenacin } \\
\text { succinate }\end{array}$ & 27 & $62 \pm 7.25$ & 5 mg/day & 12 weeks & $\begin{array}{l}\text { AEs, OABSS, OAB-q } \\
\text { SF 6, OAB-q SF } 13 \\
\text { and PGI-I }\end{array}$ \\
\hline Peters & 2009 & America & Mixed & PTNS & 41 & $57.5 \pm 15.2$ & $\begin{array}{l}\text { Once/week for } \\
30 \mathrm{~min}\end{array}$ & 12 weeks & $\begin{array}{l}\text { Micturition, nocturia, } \\
\text { urge incontinence, } \\
\text { urgency, voided vol } \\
\text { and AEs }\end{array}$ \\
\hline \multirow[t]{2}{*}{ Preyer } & \multirow[t]{2}{*}{2015} & \multirow[t]{2}{*}{ Austria } & \multirow[t]{2}{*}{ Female } & PTNS & 16 & $57.4 \pm 9.5$ & $\begin{array}{l}\text { Once/week for } \\
30 \mathrm{~min}\end{array}$ & 3 months & \multirow[t]{2}{*}{$\begin{array}{c}\text { Micturition, urge } \\
\text { incontinence and AEs }\end{array}$} \\
\hline & & & & Tolterodine & 16 & $55.8 \pm 16.2$ & 2 mg/day & 3 months & \\
\hline \multirow[t]{2}{*}{ Kızılyel } & \multirow[t]{2}{*}{2015} & \multirow[t]{2}{*}{ Turkey } & \multirow[t]{2}{*}{ Female } & PTNS & 10 & $41.00 \pm 14.49$ & $\begin{array}{l}\text { Once/week for } \\
30 \mathrm{~min}\end{array}$ & 12 weeks & \multirow{2}{*}{$\begin{array}{c}\text { Micturition, nocturia, } \\
\text { urge incontinence and } \\
\text { OABSS }\end{array}$} \\
\hline & & & & Tolterodine & 10 & $36.30 \pm 6.11$ & 4 mg/day & 12 weeks & \\
\hline Manríquez & 2016 & Chile & Female & TTNS & 34 & $54.5 \pm 16.5$ & $\begin{array}{l}\text { Twice/week for } \\
30 \mathrm{~min}\end{array}$ & 12 weeks & $\begin{array}{l}\text { Micturition, urgency, } \\
\text { urge incontinence and } \\
\text { AEs }\end{array}$ \\
\hline
\end{tabular}

SD, standard deviation; PTNS, percutaneous tibial nerve stimulation; TTNS, transcutaneous tibial nerve stimulation; AEs, adverse events; PGI-I, Patien Global Impression of Improvement questionnaire; OAB-q SF 6, Overactive Bladder questionnaire Short Form 6 items; OAB-q SF 13, Overactive Bladder questionnaire Short Form 13 items; OABSS, Overactive Bladder Symptom Score.

succinate in 2 studies $(18,19)$ and tolterodine in 3 studies $(14,16,17)$. The gender of patients was mixed in only one study (16), in which $96 \%$ and $92 \%$ patients were female in the TNS group and ACDs group respectively. Besides, all of the patients were female in the other studies $(14,15,17-19)$.

\section{Quality assessment}

For the quality assessment of the included RCTs, Figure S1 showed that 4 RCTs (15-18) described their methods of randomization and 2 RCTs $(14,19)$ did not show their specific methods of randomization. Thus, we appraised those RCTs without stating their methods of randomization as unclear risk of adequate sequence generation. Only two RCT $(17,18)$ mentioned allocation concealment and other RCTs $(14-16,19)$ did not make mention of allocation concealment. Blind methods were not adopted in all of the studies. Therefore, all RCTs were considered with high risk of blinding of participants and personnel. As we did not detect any risks regarding to other bias, we judged all the included RCTs with low risk of other bias.

\section{Outcomes}

As revealed in Figure $2 \mathrm{~A}$, five studies assessed the scores of micturition. The pooled MD for micturition was -0.75 ( $95 \%$ CI: -1.78 to $0.28, \mathrm{P}=0.16$ ), which indicated that $\mathrm{TNS}$ had no statistically significant better effect on reducing micturition. Figure $2 B$ revealed details of 3 studies mentioning nocturia. The pooled MD was -1.11 (95\% CI: -2.93 to $0.72, \mathrm{P}=0.23$ ), indicating no statistically significant difference between two interventions. Figure $2 C$ showed studies comparing TNS 
A Micturition

$\begin{array}{llll}\text { Study or Subgroup Mean SD Total Mean SD Total Weight IV, Random, 95\% C } & \text { Mean Difference }\end{array}$

\begin{tabular}{lllllllll}
\hline Kizilyel 2015 & 8.9 & 0.88 & 10 & 10.57 & 0.5 & 10 & $37.0 \%$ & $-1.67[-2.30,-1.04]$
\end{tabular}

$\begin{array}{lllllllll}\text { Manrı' quez } 2016 & 18 & 5.18 & 34 & 20 & 10.4 & 30 & 5.5 \% & -2.00 \\ {[} & {[-6.11,2.11]}\end{array}$

$\begin{array}{lllllllll}\text { Oliver } 2015 & 10.4 & 4.1 & 16 & 9.1 & 3.6 & 16 & 11.1 \% & 1.30[-1.37,3.97]\end{array}$

$\begin{array}{lrrrrrrrr}\text { Peters } 2009 & 9.8 & 3 & 41 & 9.9 & 3.8 & 43 & 23.1 \% & -0.10[-1.56,1.36]\end{array}$

$\begin{array}{lllllllll}\text { Vecchioli } 2013 & 9.4 & 1.9 & 16 & 10 & 2.1 & 14 & 23.4 \% & -0.60\end{array}[-2.04,0.84]$

Total $(95 \% \mathrm{Cl})$

117

$113 \quad 100.0 \%-0.75[-1.78,0.28]$

Heterogeneity: $\mathrm{Tau}^{2}=0.65 ; \mathrm{Chi}^{2}=8.50, \mathrm{df}=4(\mathrm{P}=0.07) ; \mathrm{I}^{2}=53 \%$

Test for overall effect: $Z=1.42(P=0.16)$

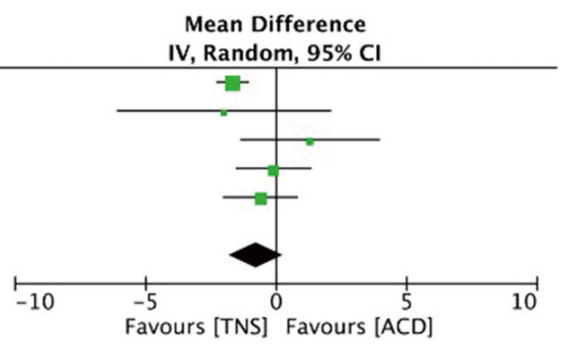

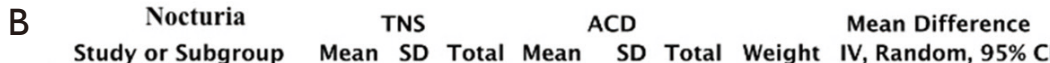

\begin{tabular}{lllllllll}
\hline Kızılyel 2015 & 2.03 & 0.5 & 10 & 4.93 & 0.94 & 10 & $33.6 \%$ & $-2.90[-3.56,-2.24]$
\end{tabular}

$\begin{array}{lrllllllll}\text { Peters 2009 } & 1.7 & 1.1 & 41 & 1.9 & 1.6 & 43 & 33.9 \% & -0.20[-0.78,0.38]\end{array}$

$\begin{array}{lllllllll}\text { Vecchioli } 2013 & 1.7 & 0.9 & 16 & 1.9 & 1.4 & 14 & 32.6 \% & -0.20\end{array}[-1.06,0.66]$

Total $(95 \% \mathrm{Cl})$

67

$67 \quad 100.0 \%-1.11[-2.93,0.72]$

Heterogeneity: $\mathrm{Tau}^{2}=2.47 ; \mathrm{Chi}^{2}=41.88, \mathrm{df}=2(\mathrm{P}<0.00001) ; \mathrm{I}^{2}=95 \%$

Test for overall effect: $Z=1.19(P=0.23)$

C

Urge incontinence TNS

ACD

ACD Mean Difference

Study or Subgroup Mean SD Total Mean SD Total Weight IV, Fixed, $95 \% \mathrm{CI}$

\begin{tabular}{lllllllll}
\hline Kizilyel 2015 & 0.13 & 1.23 & 10 & 1.93 & 0.86 & 10 & $36.0 \%$ & -1.80 [-2.73, -0.87]
\end{tabular}

$\begin{array}{llllllllll}\text { Peters 2009 } & 1.2 & 1.6 & 41 & 1.8 & 2.5 & 43 & 39.0 \% & -0.60[-1.49,0.29]\end{array}$

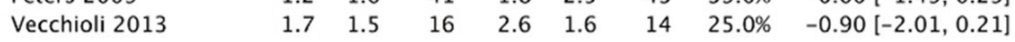

Total $(95 \% \mathrm{Cl}) \quad 67 \quad 67 \quad 100.0 \%-1.11[-1.66,-0.55]$

Heterogeneity: $\mathrm{Chi}^{2}=3.50, \mathrm{df}=2(\mathrm{P}=0.17) ; \mathrm{I}^{2}=43 \%$

Test for overall effect: $Z=3.89(P=0.0001)$

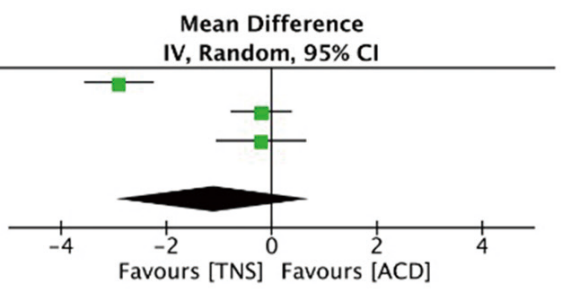

D Urgency

Study or Subgroup Mean SD Total Mean SD Total Weight IV, Fixed, 95\% CI

\begin{tabular}{lllllllll}
\hline Manrı' quez 2016 & 5 & 11.1 & 34 & 4.5 & 20 & 30 & $2.8 \%$ & $0.50[-7.57,8.57]$
\end{tabular}

$\begin{array}{lllllllll}\text { Peters } 2009 & 3.9 & 2.8 & 41 & 4.5 & 3.6 & 43 & 97.2 \% & -0.60[-1.98,0.78]\end{array}$

Total $(95 \% \mathrm{Cl})$

Heterogeneity: $\mathrm{Chi}^{2}=0.07, \mathrm{df}=1(\mathrm{P}=0.79) ; \mathrm{I}^{2}=0 \%$

Test for overall effect: $Z=0.82(P=0.41)$

$73100.0 \%-0.57[-1.93,0.79]$

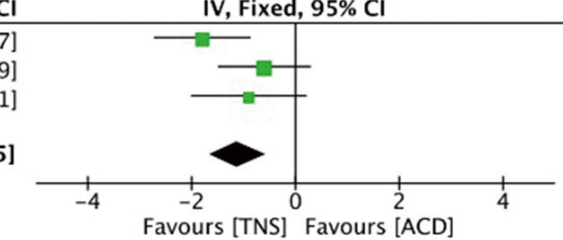

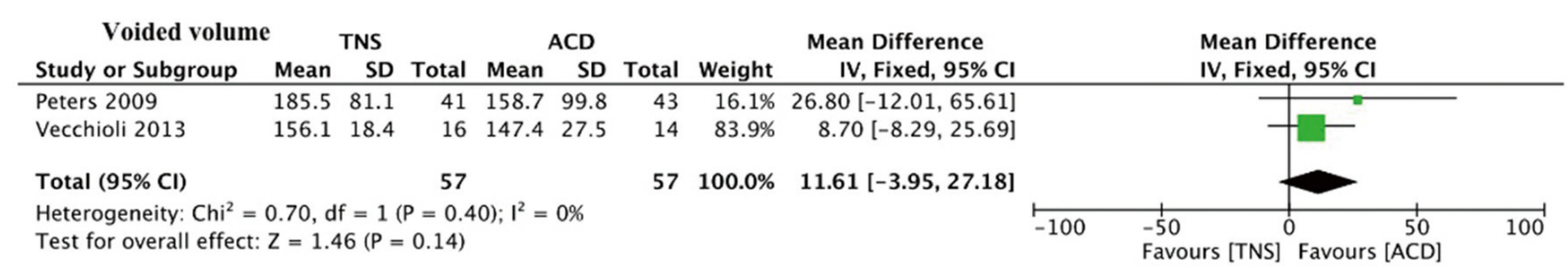

Figure 2 Forest plot for the changes of micturition per day, nocturia per night, urgency episodes per day, incontinence episodes per day and voided volume each time. TNS, tibial nerve stimulation; ACD, anticholinergic drug.

with ACDs in terms of urge incontinence. The pooled MD for urge incontinence was -1.11 (95\% CI: -1.66 to $-0.55, \mathrm{P}<0.001)$, indicating a significant stronger power in TNS for reducing urge incontinence. In terms of urgency and voided volume, Figure $2 D, E$ displays meta-analysis comparing TNS with ACDs. The pooled MDs were -0.57 (95\% CI: -1.93 to $0.79, \mathrm{P}=0.41$ ) and 11.61 (95\% CI: -3.95 to $27.18, \mathrm{P}=0.14)$ respectively, which indicated that there was no statistically significant difference between the two interventions on decreasing urgency and increasing voided volume.

As displayed in Figure $3 A, B$, the pooled MDs for change of OAB-qSF 6 and OAB-qSF13 were -0.13 (95\% CI: -0.51 to $0.26, \mathrm{P}=0.52$ ) and -0.20 (95\% CI: -0.61 to $0.21, \mathrm{P}=0.34$ ) respectively, indicating no statistically significant difference on the effect of improving OAB-qSF 6, OAB-qSF13. In the assessment of PGI-I (Figure 3C), the pooled MD was -0.46 (95\% CI: -0.84 to $-0.08, \mathrm{P}=0.02$ ), which indicated that TNS had a better power on the effect of improving PGI-I than ACDs. 


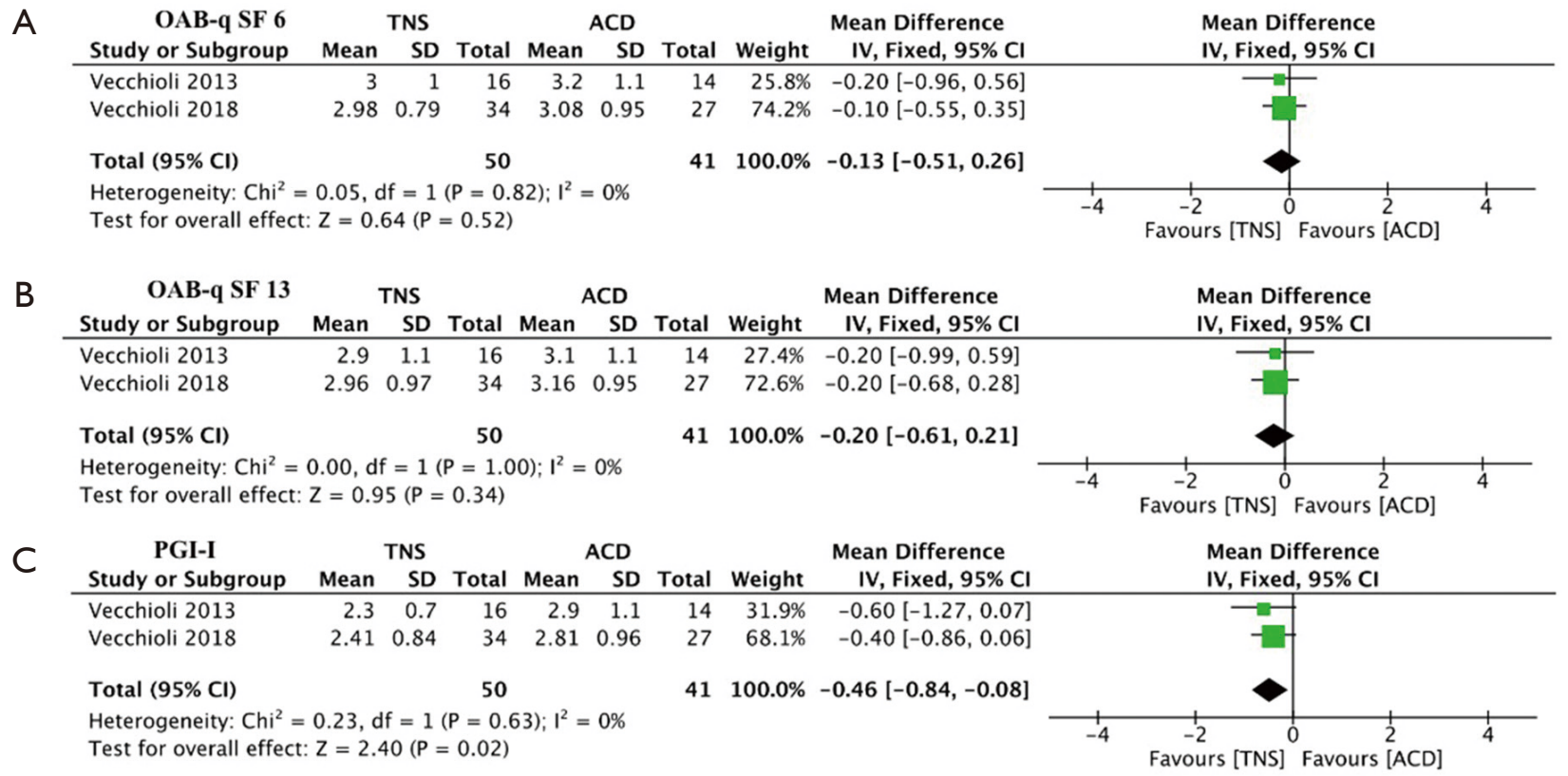

Figure 3 Forest plot for the changes of PGI-I, OAB-q SF 6 and OAB-q SF 13. PGI-I, Patien Global Impression of Improvement questionnaire; OAB-q SF 6, Overactive Bladder questionnaire Short Form 6 items; OAB-q SF 13, Overactive Bladder questionnaire Short Form 13 items; TNS, tibial nerve stimulation; ACD, anticholinergic drug.

\begin{tabular}{|c|c|c|c|c|c|c|c|c|c|}
\hline \multirow{2}{*}{$\begin{array}{l}\text { Discontinuation } \\
\text { Study or Subgroup }\end{array}$} & \multicolumn{2}{|c|}{ TNS } & \multicolumn{2}{|c|}{ ACD } & Weight & \multirow[t]{2}{*}{$\begin{array}{c}\text { Odds Ratio } \\
\text { M-H, Fixed, 95\% Cl }\end{array}$} & \multicolumn{3}{|c|}{$\begin{array}{c}\text { Odds Ratio } \\
\text { M-H, Fixed, } 95 \% \mathrm{Cl}\end{array}$} \\
\hline & 0 & 36 & 3 & 34 & $22.0 \%$ & & $\longrightarrow$ & & \\
\hline Oliver 2015 & 1 & 18 & 2 & 18 & $11.7 \%$ & $0.47[0.04,5.71]$ & & & \\
\hline Vecchioli 2013 & 0 & 16 & 2 & 16 & $15.0 \%$ & $0.18[0.01,3.97]$ & $\leftarrow$ & & \\
\hline Vecchioli 2018 & 0 & 34 & 8 & 35 & $51.2 \%$ & $0.05[0.00,0.85]$ & & & \\
\hline Total $(95 \% \mathrm{Cl})$ & & 104 & & 103 & $100.0 \%$ & $0.13[0.03,0.51]$ & & & \\
\hline Total events & 1 & & 15 & & & & & & \\
\hline $\begin{array}{l}\text { Heterogeneity: } \mathrm{Chi}^{2}= \\
\text { Test for overall effect }\end{array}$ & $\begin{array}{l}1.52, \mathrm{df} \\
\mathrm{Z}=2.93\end{array}$ & $\begin{array}{l}=3(P \\
(P=0\end{array}$ & $\begin{array}{l}=0.68) ; 1 \\
0.003)\end{array}$ & $\mathrm{I}^{2}=0 \%$ & & & $\begin{array}{c}1 \\
0.1 \\
\text { Favours [TNS] }\end{array}$ & $\begin{array}{cc}1 & 1 \\
\text { Favours [ACD] }\end{array}$ & 100 \\
\hline
\end{tabular}

Figure 4 Forest plot for meta-analysis of discontinuation because of an adverse event. TNS, tibial nerve stimulation; ACD, anticholinergic drug.

Sensitivity analysis was conducted, and when ruling out the study of Peters 2009 and Preyer 2015 respectively, the pooled MDs of change of micturition were -1.39 (95\% CI: -1.94 to $0.83, \mathrm{P}<0.001)$ and -1.32 (95\% CI: -1.85 to 0.79 , $\mathrm{P}<0.001$ ), which meant TNS might have a better effect in improving micturition compared with ACDs.

\section{Safety assessment}

With regard to safety profile, there was no severe adverse event in the current study. The incidence of any side effects is $11.1 \%$ and $33.7 \%$ in the TNS cohort and the ACDs cohort respectively and most of the side effects were mild or moderate, including dry mouth and constipation in the ACDs group and puncture pain in the TNS group. As shown in Figure 4, the incidence of discontinuation because of an AE was compared between the TNS group and ACDs group and the relevant OR was 0.13 (95\% CI: 0.03 to $0.51, \mathrm{P}=0.003$ ), indicating that TNS had significantly less discontinuation because of an $\mathrm{AE}$ than ACDs.

\section{Discussion}

TNS and ACDs are both efficient on improving $\mathrm{OAB}$ 
symptoms $(12,23)$. Several systemic reviews have demonstrated the efficiency and safety of TNS in the treatment of $\mathrm{OAB}(11,24,25)$. Over the past decade, two meta-analyses have shown that TNS had significant better improvements on the symptoms of $\mathrm{OAB}$ comparing with sham treatment $(26,27)$. However, due to the lack of enough studies, these two meta-analyses had no sufficient efficiency to show any superiority on improving $\mathrm{OAB}$ symptoms between TNS and ACDs. To the best of our knowledge, the present meta-analysis is the first head to head meta-analysis directly comparing TNS and ACDs in the treatment of $\mathrm{OAB}$.

In this meta-analysis, all of the included studies were RCTs, which had a relatively higher level of evidence comparing with non-RCTs. Because most of the included patients were not refractory patients of $\mathrm{OAB}$ and some of them were naïve to treatment, the outcomes might slightly be influenced by the resistance to ACDs. We found that TNS had a comparable effect on the improvement of urgency, micturition, nocturia and voiding volume and better improvement of urge incontinence compared with ACDs. When ruling out the study of Peters 2009 or Preyer 2015, the sensitivity analysis even showed that TNS had a better effect of the decrease of micturition over ACDs $(16,17)$. All of the included RCTs have demonstrated that short term TNS had significant effect on the improvement of OAB. However, all of the included studies did not assess the duration of TNS and studies evaluating the long-term therapy of TNS seem to be rare so far. MacDiarmid et al. offered an additional 9 months of TNS treatment for the patients, who were randomized to TNS group in the Overactive Bladder Innovative Therapy Trail and have already received 12 weeks of TNS therapy, to evaluate the sustained theraputic efficacy (28). They found evidences that TNS had statistically significant OAB symptoms improvement in terms of frequency, urge incontinence, nocturia and voided volume from 12 weeks to 12 months, which means that TNS had a durable and long-term effect on the OAB therapy.

Except for comparing the improvements of symptoms, we also included commonly used questionnaires, involving PGI-I, OAB-q SF 6 and OOAB-q SF 13, to assess the impact of OAB symptoms on patient's quality of life (QoL) and the patient impression of improvement. Our meta-analysis found that TNS had comparable effect on improving OAB-q SF 6 and OAB-q SF13 and better effect on improving PGI-I than ACDS. Vecchioli et al. used the Overactive Bladder Symptom Score (OABSS) questionnaire to evaluate the improvements in $\mathrm{OAB}$ symptoms and they found that TNS had a greater effectiveness than solifenacin (18). Souto et al. evaluated patients at weeks 0,12 , and 24 with other forms, including International Consultation on Incontinence-OAB (ICIQ-OAB), questionnaires International Consultation on Incontinence-Short Form (ICIQ-SF) and Symptom bother and they found TNS was more effective for improvement of clinical symptoms of $\mathrm{OAB}$ and QoL (29).

The tolerance of ACDs was poor for patients with $\mathrm{OAB}$, due to the systemically anticholinergic side effects including dry mouth, constipation, dizziness, visual blurriness, headache, diarrhea and fatigue. Gopal et al. used a large administrative database involving 29,369 patients with lower urinary tract symptoms to assess the discontinuation of ACDs. They found that the discontinuation was high with a rate of $54-71 \%$ in different class of medication at 6 months and the median time for overall discontinuation was short about 4.76 months (30). Generally, TNS had rare side effects and the common side effects contain puncture pain, swelling, hematuria, headache, leg cramps, vasovagal response and intermittent foot/toe pain $(16,31,32)$. In our meta-analysis, the incidence of any side effect is $11.1 \%$ and $33.7 \%$ in the TNS cohort and the ACDs cohort respectively and the discontinuation because of an AEs in the ACDs cohort was significantly higher than that of TNS cohort. In other words, the tolerance of TNS is better than that of ACDs, and this tolerance could even be much better if we adopt transcutaneous TNS (TTNS), which abandons the traditional needle and uses the superficial electrode to stimulate the nerve, making it less invasive and more tolerable (15).

Though the efficiency and side effects are the most important factors influencing the option of therapeutic methods, the cost of treatment also influences the preference of patients. However, there was no information about the cost in the included studies. Chen at al compared the cost-effectiveness of TNS and extended release tolterodine for the treatment of OAB (33). They found that the incremental cost-effectiveness ratio for every 100 patients in the TNS cohorts was $\$ 70,754$ per quality adjusted life-year gained compared with the extended release tolterodine cohorts, which means that TNS was not cost-effective compared with extended release tolterodine. However, these data refer to a single antimuscarinic drug and perhaps can't be generalized to all. Thus, the costeffectiveness of TNS and ACDs still needs to be assessed further. 
Although our meta-analysis showed that TNS had comparable therapeutic effects on the improvement of most $\mathrm{OAB}$ symptoms and pointed out some superiority of TNS over ACDs on the assessment of urge incontinence and PGI-I, there were some limitations worth mention. Firstly, all of the included RCTs were not blinded, which may lead to some unavoidable biases influencing the results of this meta-analysis. Secondly, the dosage, variety, frequency, duration and cycle of TNS and ACDs varied a lot in different studies and these variations could also be found in the baseline information and measurement parameters. Thirdly, all of the studies only assessed the short-time efficiency of TNS and ACDs and the long-term effect needs to be assessed in the subsequent follow-up. Besides, the included RCTs can't provide detailed information about if patients had previously failed ACDs therapy before entry to the RCTs. Patients previously failing ACDs therapy or not may respond to the ACDs therapy differently. Therefore, more high-quality RCTs with large scale and long-time follow-up are strongly necessary to evaluate the efficiency of TNS and ACDs.

\section{Conclusions}

In this meta-analysis, we confirm that TNS has comparable therapeutic effects on the improvement of OAB symptoms including micturition, nocturia, urgency and voiding volume but has better effect on urge incontinence compared with ACDs. Compared with patients receiving ACDs, those receiving TNS have a similar improvement of QOL scores regarding OAB-q SF 6 and OAB-q SF13 but had better impression on the improvement of OAB in terms of PGI-I. Besides, we also found that TNS, with less discontinuation, might be more tolerable compared with ACDs. TNS may be an alternative option of ACDs for the treatment of OAB.

\section{Acknowledgments}

Funding: This work was supported by the 1.3 .5 project for disciplines of excellence, West China Hospital, Sichuan University (No. ZY2016104).

\section{Footnote}

Reporting Checklist: The authors have completed the PRISMA reporting checklist. Available at http://dx.doi. org/10.21037/apm-21-339
Peer Review File: Available at http://dx.doi.org/10.21037/ apm-21-339

Conflicts of Interest: All authors have completed the ICMJE uniform disclosure form (available at http://dx.doi. org/10.21037/apm-21-339). The authors have no conflicts of interest to declare.

Etbical Statement: The authors are accountable for all aspects of the work in ensuring that questions related to the accuracy or integrity of any part of the work are appropriately investigated and resolved.

Open Access Statement: This is an Open Access article distributed in accordance with the Creative Commons Attribution-NonCommercial-NoDerivs 4.0 International License (CC BY-NC-ND 4.0), which permits the noncommercial replication and distribution of the article with the strict proviso that no changes or edits are made and the original work is properly cited (including links to both the formal publication through the relevant DOI and the license). See: https://creativecommons.org/licenses/by-nc-nd/4.0/.

\section{References}

1. Billecocq S, Bo K, Dumoulin C, et al. An International Urogynecological Association (IUGA)/International Continence Society (ICS) joint report on the terminology for the conservative and non-pharmacological management of female pelvic floor dysfunction. Prog Urol 2019;29:183-208.

2. Stewart WF, Van Rooyen JB, Cundiff GW, et al. Prevalence and burden of overactive bladder in the United States. World J Urol 2003;20:327-36.

3. Irwin DE, Milsom I, Hunskaar S, et al. Population-based survey of urinary incontinence, overactive bladder, and other lower urinary tract symptoms in five countries: results of the EPIC study. Eur Urol 2006;50:1306-14; discussion 1314-5.

4. Powell LC, Szabo SM, Walker D, et al. The economic burden of overactive bladder in the United States: A systematic literature review. Neurourol Urodyn 2018;37:1241-9.

5. Usmani SA, Reckenberg K, Johnson O, et al. Relative Risk of Adverse Events and Treatment Discontinuations Between Older and Non-Older Adults Treated with Antimuscarinics for Overactive Bladder: A Systematic 
Review and Meta-Analysis. Drugs Aging 2019;36:639-45.

6. Sussman D, Yehoshua A, Kowalski J, et al. Adherence and persistence of mirabegron and anticholinergic therapies in patients with overactive bladder: a real-world claims data analysis. Int J Clin Pract 2017;71:e12824.

7. Schmidt RA, Jonas U, Oleson KA, et al. Sacral nerve stimulation for treatment of refractory urinary urge incontinence. Sacral Nerve Stimulation Study Group. J Urol 1999;162:352-7.

8. Starkman JS, Wolter CE, Scarpero HM, et al. Management of refractory urinary urge incontinence following urogynecological surgery with sacral neuromodulation. Neurourol Urodyn 2007;26:29-35; discussion 36.

9. Groen J, Bosch JL. Neuromodulation techniques in the treatment of the overactive bladder. BJU Int 2001;87:723-31.

10. van Balken MR, Vandoninck V, Gisolf KW, et al. Posterior tibial nerve stimulation as neuromodulative treatment of lower urinary tract dysfunction. J Urol 2001;166:914-8.

11. Gaziev G, Topazio L, Iacovelli V, et al. Percutaneous Tibial Nerve Stimulation (PTNS) efficacy in the treatment of lower urinary tract dysfunctions: a systematic review. BMC Urol 2013;13:61.

12. Wang M, Jian Z, Ma Y, et al. Percutaneous tibial nerve stimulation for overactive bladder syndrome: a systematic review and meta-analysis. Int Urogynecol J 2020;31:2457-71.

13. Sherif H, Khalil M, Omar R. Management of refractory idiopathic overactive bladder: intradetrusor injection of botulinum toxin type A versus posterior tibial nerve stimulation. Can J Urol 2017;24:8838-46.

14. Kızılyel S, Karakeçi A, Ozan T, et al. Role of percutaneous posterior tibial nerve stimulation either alone or combined with an anticholinergic agent in treating patients with overactive bladder. Turk J Urol 2015;41:208-14.

15. Manríquez V, Guzmán R, Naser M, et al. Transcutaneous posterior tibial nerve stimulation versus extended release oxybutynin in overactive bladder patients. A prospective randomized trial. Eur J Obstet Gynecol Reprod Biol 2016;196:6-10.

16. Peters KM, Macdiarmid SA, Wooldridge LS, et al. Randomized trial of percutaneous tibial nerve stimulation versus extended-release tolterodine: results from the overactive bladder innovative therapy trial. J Urol 2009;182:1055-61.

17. Preyer O, Umek W, Laml T, et al. Percutaneous tibial nerve stimulation versus tolterodine for overactive bladder in women: a randomised controlled trial. Eur J Obstet Gynecol Reprod Biol 2015;191:51-6.
18. Vecchioli-Scaldazza C, Morosetti C. Effectiveness and durability of solifenacin versus percutaneous tibial nerve stimulation versus their combination for the treatment of women with overactive bladder syndrome: a randomized controlled study with a follow-up of ten months. Int Braz J Urol 2018;44:102-8.

19. Vecchioli-Scaldazza C, Morosetti C, Berouz A, et al. Solifenacin succinate versus percutaneous tibial nerve stimulation in women with overactive bladder syndrome: results of a randomized controlled crossover study. Gynecol Obstet Invest 2013;75:230-4.

20. Higgins JP, Thompson SG, Deeks JJ, et al. Measuring inconsistency in meta-analyses. BMJ 2003;327:557-60.

21. DerSimonian R. Meta-analysis in the design and monitoring of clinical trials. Stat Med 1996;15:1237-48; discussion 1249-52.

22. Blunch NJ. Statistical analysis of data from clinical and retrospective studies. Ugeskr Laeger 1976;138:401-7.

23. Lightner DJ, Gomelsky A, Souter L, et al. Diagnosis and Treatment of Overactive Bladder (Non-Neurogenic) in Adults: AUA/SUFU Guideline Amendment 2019. J Urol 2019;202:558-63.

24. Moossdorff-Steinhauser HF, Berghmans B. Effects of percutaneous tibial nerve stimulation on adult patients with overactive bladder syndrome: a systematic review. Neurourol Urodyn 2013;32:206-14.

25. Biemans JM, van Balken MR. Efficacy and effectiveness of percutaneous tibial nerve stimulation in the treatment of pelvic organ disorders: a systematic review. Neuromodulation 2013;16:25-33; discussion 33.

26. Burton C, Sajja A, Latthe PM. Effectiveness of percutaneous posterior tibial nerve stimulation for overactive bladder: a systematic review and meta-analysis. Neurourol Urodyn 2012;31:1206-16.

27. Wibisono E, Rahardjo HE. Effectiveness of Short Term Percutaneous Tibial Nerve Stimulation for Nonneurogenic Overactive Bladder Syndrome in Adults: A Meta-analysis. Acta Med Indones 2015;47:188-200.

28. MacDiarmid SA, Peters KM, Shobeiri SA, et al. Long-term durability of percutaneous tibial nerve stimulation for the treatment of overactive bladder. J Urol 2010;183:234-40.

29. Souto SC, Reis LO, Palma T, et al. Prospective and randomized comparison of electrical stimulation of the posterior tibial nerve versus oxybutynin versus their combination for treatment of women with overactive bladder syndrome. World J Urol 2014;32:179-84.

30. Gopal M, Haynes K, Bellamy SL, et al. Discontinuation rates of anticholinergic medications used for the treatment 
of lower urinary tract symptoms. Obstet Gynecol 2008;112:1311-8.

31. Peters KM, Carrico DJ, Perez-Marrero RA, et al. Randomized trial of percutaneous tibial nerve stimulation versus Sham efficacy in the treatment of overactive bladder syndrome: results from the SUmiT trial. J Urol 2010;183:1438-43.

32. van der Pal F, van Balken MR, Heesakkers JP, et al.
Percutaneous tibial nerve stimulation in the treatment of refractory overactive bladder syndrome: is maintenance treatment necessary? BJU Int 2006;97:547-50.

33. Chen HW, Bercik RS, Werner EF, et al. Cost-effectiveness of percutaneous tibial nerve stimulation versus extended release tolterodine for overactive bladder. J Urol 2012;187:178-84.
Cite this article as: Xiong SC, Peng L, Hu X, Shao YX, Wu K, $\mathrm{Li}$ X. Effectiveness and safety of tibial nerve stimulation versus anticholinergic drugs for the treatment of overactive bladder syndrome: a meta-analysis. Ann Palliat Med 2021;10(6):6287-6296. doi: 10.21037/apm-21-339 


\section{Supplementary}

Random sequence generation (selection bias)

Allocation concealment (selection bias) Blinding of participants and personnel (performance bias)

Blinding of outcome assessment (detection bias) Incomplete outcome data (attrition bias) Selective reporting (reporting bias)
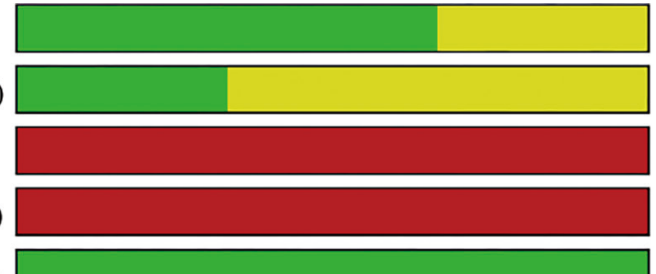

$$
\text { Other bias }
$$
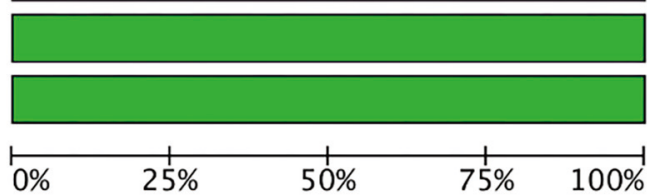

Low risk of bias

Unclear risk of bias

High risk of bias

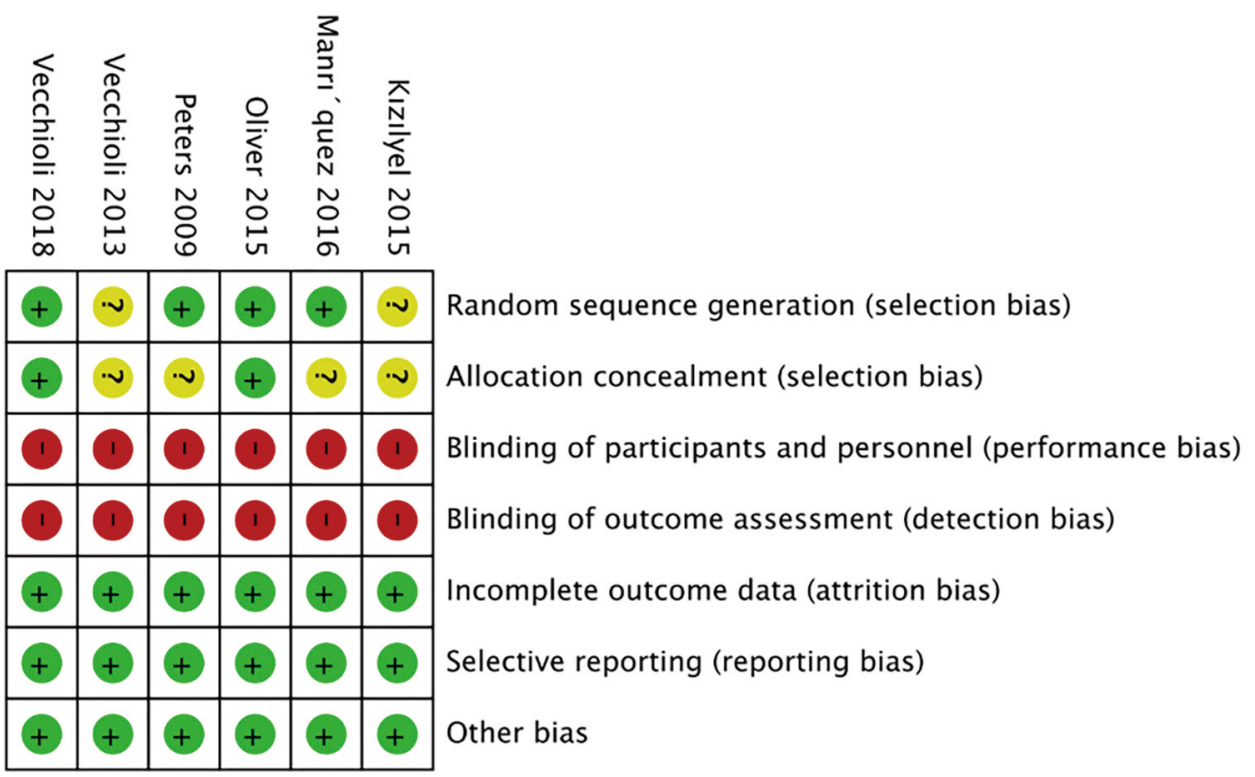

Figure S1 Risk of bias for randomized controlled trials. 